\title{
INSTRUCTIONAL LEADERSHIP: THE EFFECT OF TEACHING SELF-EFFICACY
}

\author{
Muflih Ma'mun a*, Asep Suryana ${ }^{b}$ \\ a* Prodi PIAUD STAI Darul Falah Bandung Barat \\ Jl. Raya Cihampelas No. 96, Bandung Barat, Jawa Barat, Indonesia, ganungadpend@gmail.com \\ ${ }^{\mathrm{b}}$ Prodi Administrasi Pendidikan Universitas Pendidikan Indonesia \\ Jl. Dr. Setiabudhi No. 2Dr. Setiabudi No.229, Isola, Kota Bandung, Jawa Barat, Indonesia, doef@upi.edu
}

\begin{abstract}
The principal as leader who has the role to support and facilitate the needs of teachers in teaching activities. When the principal's role can be carried out properly, it will have an impact on the teaching efficacy of teachers. This study examines the effect of instructional leadership on the teaching self-efficacy of teachers by taking a sample of 147 teachers. Data analysis techniques using regression analysis. The results showed that instructional leadership had a significant effect on the teaching self-efficacy despite its low effect. As a recommendation, school principals as instructional leaders in improving teaching efficacy should not only be equipped with pedagogical knowledge, but must also be strengthened by knowledge school management capabilities.
\end{abstract}

Keywords: instructional leadership, teaching self-efficacy

\section{INTRODUCTION}

Self-efficacy is a concept introduced by Bandura (1997) with social cognitive theory as construction. Social cognitive theory is an approach in understanding individual cognition, actions, motivations, and emotions with the assumption that individuals have the capacity to carry out self-reflection and selfregulation that actively shape the surrounding environment. In view of this theory, the cognitive dimensions of the environment, behavior, and personality are interrelated. Individuals in carrying out activities / work are not solely driven by forces that originate from within themselves, but are also driven by external factors through a series of cognitive processes; symbolization, forward thinking, observation, self-regulation, to self-reflection.
The self-efficacy is the teacher's confidence in the ability possessed to be able to teach well. The existence of self-efficacy indicates psychological maturity in the teacher. Teachers with self-efficacy have extra energy in using and empowering teaching resources effectively and efficiently for students' success in learning. In addition, teachers with selfefficacy also show emotional maturity by not easily feeling stressed, resistant to pressure, and calm in the face of unpleasant situations.

Teachers with high teaching self-efficacy mentally and behavior showed better readiness at work compared to teachers with low self-efficacy. Diligent, tenacious, not easily give up, not easily discouraged, not easily stressed when experiencing failure, and strive to improve performance standards is an 
indication of the maturity of self-efficacy in a teacher.

Research that has been done shows that the teaching self-efficacy has a positive impact on student learning achievement (Rew, 2013; Guo, Piasta, Justice, \& Kaderavek, 2010; Caprara, Barbaranelli, Steca, \& Malone, 2006; Muijs \& Reynolds, 2002; Ross, 1992), positive student attitudes (Gibson \& Dembo, 1984), and the level of student efficacy (Schunk, 1997; Pintrich \& De Groot, 1990; Schunk \& Swartz, 1992a, 1992b; Zimmerman \& Martinez-Pons, 1990).

Self-efficacy as one of the factors influencing teaching success is not in doubt. Self-efficacy affects positively as do other factors such as: motivation, compensation, reward and punishment, attribution, self-appreciation, availability of facilities, leadership, climate and school culture, and supervision. What distinguishes between self-efficacy with the factors mentioned above namely self-efficacy is formed from the results of the process of cognition, behavior, and the environment carried out by individuals.

Teaching self-efficacy is divided into outcome efficacy and expectancy efficacy. The effectiveness of output is the teacher's confidence in achieving the expected target in teaching activities. While the expectancy efficacy is the efficacy of a more specific teaching situation. In other terms, the efficacy of results is also called general teaching efficacy (Hoy and Woolfolk, 1990; Tschannen-Moran and Woolfolk Hoy, 2001). While the efficacy of hope, some experts call it personal teaching efficacy (Gibson and Dembo 1984; Hoy and Woolfolk 1990; Tschannen-Moran and Woolfolk Hoy 2001).

Teaching self-efficacy views the experiences of personal and other successes in teaching, the persuasion of others and social conditions in the school environment, as well as the emotional and physical conditions at the time of teaching as factors that influence the success of teachers in teaching. However, in the study of organizational behavior, the teaching self-efficacy can be formed, developed, and improved through the mechanism of organizational systems in the form of education and training, professional development, and through the role of leadership.

The results of the preliminary study indicate that the teaching self-efficacy is influenced by external factors such as instructional leadership of school principals.

This is in line with the study of literature found by researchers that instructional leadership is one source of efficacy in social cognitive theory (Ross, Hogaboam-Gray, \& Gray, 2004; Ebmeier, 2003), enhances classroom learning through teachers, and positively influences on the knowledge and understanding, implementation of teaching, competence and efficacy of teachers individually and collectively (Blase \& Blase, 2000).

Verbal persuasion from the principal occurs through the use of power and authority through instructions or instructions to the teacher to increase the effect of teaching selfefficacy. The principal has the authority to coerce, encourage, direct, and intervene the teacher to carry out the desired activity. In situational leadership, the process of verbal persuasion can be carried out through telling, selling, participating, and delegating activities. Verbal persuasion emphasizes the forms of interaction and communication between the principal and the teacher.

The main provision to become an instructional leader is an adequate understanding of the learning process along with the content of learning content (knowledge of psychological content) as well as an understanding of management based on knowledge based management, given that almost all instructional leader activities are focused on providing and supporting increased learning.

Teaching activitiy is the main task of a teacher where the scope of assignments and responsibilities applies equally to all teachers in the school. This becomes the basis that the 
obstacles faced by teachers in learning between one teacher and the other are not much different, there is even the possibility of obstacles faced the same, only the scope of the constraints that differs according to the conditions, characteristics, areas of study, and the ability of teachers and external factors.

Teachers who are successful in overcoming obstacles and problems they face can be used as role models of success for other teachers through a modeling mechanism. This is where the importance of the implementation of supervision through the supervisor's role as a provider of information that is relevant to the teacher.

\section{Instructional Leadership}

Instructional leadership was coined by Hallinger and Murphy (1997) through consistent research in the 1980s. The results of research conducted, there is a continuation of the results obtained that instructional leadership contributes significantly to school achievement and student learning (school and student achievement). The results of this study ultimately open up new horizons for practitioners of educational administration in exploring further and developing this leadership model.

Instructional leadership can be defined as the efforts of principals to indirectly influence student achievement by creating instructional organizations in their schools through participatory action and by building a school climate and culture marked by clearly communicated goals and high expectations of academic achievement and social behavior (Heck, et al in Hoy, 2014: 668).

The contribution of instructional leadership to school achievement cannot be denied, if it is based on the results of research that has been done. This leadership contribution significantly impacts student achievement (Sahin, 2011; Blasé \& Blasé, 2004; Deal \& Peterson, 1998; Hallinger \& Murphy, 1985; Weber, 1996; Hoy \& Hoy, 2003; and Sisman, 2004). Principals who implement instructional leadership will systematically influence student achievement (Sahin, 2011). In addition, instructional leadership also influences the formation of academic culture which is a symbol of strength and a tool in improving learning activities in schools (Sahin, 2011; Cafoglu, 1995; Hargreaves, Earl, Moore, \& Meaning, 2001; Hart \& Bredeson, 1996; Harris 2002; Hopkins, 2000; Kotter \& Heskett, 1992; Masland, 1985; Peterson, 2002; Slater, Goldring, Bolman, Thurston, \& Crow, 1994).

Instructional leadership focuses on teaching and learning and on the behavior of teachers in working with students. Leaders' influence is directed at student learning via teachers. Thus a principal with relevant knowledge of the mandated national curriculum and who uses interpersonal social skills could motivate and inspire teachers who actually teach the learners. The principal's leadership influence thus impacts directly on the teachers who in turn influence the learners (Bush in Grobler,2013:179).

Being instructional leaders, principals are required to have qualified professional understanding, pedagogical skills, student learning (pupil learning), how adults learn, and human interaction (Southworth, 2002). Various forms of instructional leadership support are described in detail by the Alternative Project Certification in Administration and Curriculum (CAPAC) in (Miller \& Vruggink, 2010: 322) as follows: (a) providing the environment for instructional improvement and change, (b) providing the environment for curriculum improvement, (c) providing continuous evaluation of instructional processes and programs, (d) providing assistance to the instructional staff, (e) providing appropriate instructional programs for each student, (f) evaluating current instructional programs.

\section{Teaching Self-Efficacy}

The definition of self-efficacy is a belief in one's capability to organize and decide on a series of behaviors needed to achieve a certain goal (Bandura, 1997). Self-efficacy is a 
feeling of confidence in the success of the individual in carrying out certain tasks. Clarifying the definition given by Bandura, Luthans (2006: 347-348) states that selfefficacy is defined as one's belief in his ability to move, motivate, cognitive sources, and sources of action needed to carry out tasks in certain contexts.

Self-efficacy's concept is essentially more about the condition of the individual in perceiving one's abilities and realizing them in the form of concrete actions in the form of completing a job and trying to overcome the problems or obstacles faced. Individuals with high self-efficacy in carrying out work are considered more successful and successful compared to individuals with low levels of self-efficacy.

The efficacy in the context of carrying out the work (Luthans, 2006: 240) relates to: (a) the decision to display certain tasks in a specific context, (b) the amount of effort that will be made to complete the task, and (c) the level of endurance that will arise (other than the problem), the incompatibility of evidence or results with the difficulties encountered.

In a specific context, in the teaching and learning process, the teaching self-efficacy can be interpreted as the belief of teachers in organizing effective learning (Weasmar \& Woods in Hadjam \& Widhiarso, 2011:4). While Wheatley (2005) defines the teaching self-efficacy as confidence in the ability of self to provide something of value to students.

Teacher's belief that he or she does have the competence and skills to bring about student learning (Yeh, 2006:). Furthermore, Rew (2013:16), teaching self-efficacy represents the individual teacher's belief in his or her ability to execute certain actions or behaviors that specifically corresponds to elements of the teaching profession, such as delivering classroom instruction or improving student achievement.

Several studies have shown that the teaching self-efficacy has a significant correlation on student achievement (Rew, 2013; Guo, Piasta,
Justice, \& Kaderavek, 2010; Caprara, Barbaranelli, Steca, \& Malone, 2006; Muijs \& Reynolds, 2002; Ross, 1992). This is because teaching efficacy is closely related to teacher teaching activities in the form of reflective teaching, goal setting, and analysis of the use of teaching and learning strategies (Bandura, 1997).

\section{METHODS}

The research method used is the correlational approach with the quantitative method. Correlational approach is research conducted to obtain the level of relationship or influence of two or more variables using statistical analysis. This research was conducted in several state high schools in the Cilacap Regency, Central Java Province. Data was obtained through distributing questionnaires to 147 teachers.

Table 1.1. Regression Weights

\begin{tabular}{lrrrrr}
\hline & & & & & \\
& & & & & \\
TSE $<---$ & IL & 0.956 & 0.469 & 2.038 & 0.042 \\
\hline
\end{tabular}

Teaching self-efficacy in this study was measured through two indicators, namely personal teaching efficacy and general teaching efficacy. The instructional leadership is measured through three indicators namely defining school's mission, managing curriculum and instructional programs and promoting positive learning climate.

Statistic analysis. Hypothesis testing in this study is done by comparing the critical ratio or also called t statistic. The critical value at the $10 \%$ significance level $(0.1)$ is $>1.56$. While the critical value at the 5\% (0.05) significance level of $>1.96$ and at the $1 \%(0.1)$ significance level of $>2.58$. The critical value set in this study is $5 \%$ (0.05). The results of testing through the research hypothesis can be seen in the following regression weights table. 
Based on the table above, the hypothesis testing results are obtained where the effect of instructional leadership on teaching efficacy with a critical ratio (CR) value of 2.038 and a significance value of 0.042 indicates that the value is above the critical value and also the significance set. It can be concluded that instructional leadership has a significant effect on teaching self-efficacy.

In addition to calculating the correlation value, this study also displays a regression standard to obtain the coefficient of determination (R2) of the relationship of variables and also indicators with construct variables. The magnitude of the coefficient of determination in the calculation results is shown in the standardized regression table which is then squared to obtain the R-square value as described in the table below.

Instructional leadership affects the teaching self-efficacy of the R-square calculation of 0.094 or $9.43 \%$. This means that the teaching self-efficacy is influenced by instructional leadership by $9.43 \%$ and the rest by $90.57 \%$ is influenced by other factors.

Table 1.2 Coefficient of Determination $\left(\mathbf{R}^{2}\right)$

\begin{tabular}{ccccc}
\hline & & Estimate & $\mathrm{R}^{2}$ & $\%$ \\
TSE <--- & IL & 0.307 & 0.094 & 9.425 \\
\hline
\end{tabular}

\section{RESULTS AND DISCUSSION}

The Based on the results of previous statistical calculations, instructional leadership has significant influence on teaching self-efficacy. Based on the results of previous statistical calculations, instructional leadership has a significant influence on teaching self-efficacy. The results of this study support the findings of research conducted by Ross et al (2004) and Ebmeie (2003) that instructional leadership is one source of efficacy.

The principal can improve teaching selfefficacy by increasing understanding of the vision and mission of the school, increasing awareness of the professional responsibilities of the educator, supporting and providing opportunities for teachers to develop professional abilities (professional development), organizing induction programs for teachers, providing opportunities and support for teachers who continue their studies, and recruit prospective teachers who have the best abilities and are aligned with organizational goals (Fancera \& Bliss, 2011). Some of these efforts were made so that the teacher increased his self-confidence, that with his abilities he was able to carry out his professional responsibilities well.

The principal's relationship with teaching efficacy is not limited to efforts to manage and utilize school resources for the success of teaching teachers, but there are other functions that must also be carried out namely as a source of information (sources of information) for teachers in schools in improving selfefficacy (Bandura, 1977 ). Principals who play instructional leadership have a good vision of how to improve teacher efficacy, either by direct means through policies and programs that are made, or indirectly through harmonizing the school environment that allows teachers to learn and improve their abilities.

If returned to the concept put forward by Bandura, that the principal is the main source of information for teachers in improving the efficacy in the implementation of work, especially teaching. Information in the form of mastery experiences, for example, can be grown through collaborative efforts between teachers and principals in formulating instructional goals or school academic goals, enriching the school curriculum, learning improvement programs, enhancing and empowering learning resources, or through internal school professional groups. 
While information in the form of vicarious experiences and social persuasions by the principal can be grown through induction programs, mentoring teachers with low selfefficacy, inter-class visit programs, lesson studies, or through collegial supervision activities among teachers. The verbal persuasion is carried out by the principal through the communication process that occurs with the teacher either in the form of instructions or instructions or suggestions for obtaining feedback from the implementation of learning activities, obstacles faced by teachers, school success in academic achievement, and complaints and suggestions that arise from the community.

The contribution of instructional leadership is indirect to students, but through the teacher as a mediator because the teacher is a party that directly interacts with students. This direct relationship occurs if the principal tries to best manage and utilize all school resources; infrastructure, financial, school environment, and personnel (teachers and staff) to support student achievement. Therefore, what is emphasized in instructional leadership is the extent to which the principal is able to provide encouragement, support, and facilities to teachers to develop their capacity to carry out their duties and responsibilities as educators through the optimization of available resources.

The low influence of instructional leadership on teaching self-efficacy in researchers is due to the low ability of principals in defining school's mission. Defining school's mission is the principal's effort in describing, establishing, affirming or describing the mission of the school so that it can be understood in full by the whole school community. In a broader sense, defining school's mission is the extent to which the principal understands the school's mission and describes it in the form of policies, programs, and a series of activities in which its implementation can be carried out by school members and their success can be measured. The two main functions of instructional leaders in defining school missions are setting school goals-framing the school's goals and communicating these goals to all school members-communicating the school's goals.

Principals who play themselves as instructional leaders focus all activities on efforts to achieve school goals by involving all school members (teachers and staff) and ensure that they clearly understand what the school goals are, outlining and compiling school programs that are possible to be achieved by teachers and staff, as well as setting goals that focus on the progress of student learning periodically. This also indicates that the principal has a responsibility to convey the school goals set so that teachers and staff understand broadly and deeply so that they can provide support for the creation of a good school climate (Hallinger, 2009) there is 2 Hallinger in refrences 2003 and 2009, which one?.

The formulation of school goals as a translation of the vision and mission of the school was developed based on consideration of input, opinions, and suggestions from teachers and staff in an effort to optimize the role and support of teachers for school programs and activities. The involvement of teachers and staff in formulating school goals is intended to encourage active participation as well as the principal's strategic steps in distributing the roles and responsibilities of work so that it will have an impact on changes in behavior and ways of thinking of individuals, including changes in teachers in teaching activities given the school goals that have been set requires harmony of behavior and ways of teaching to the teacher. This means that the teacher must understand the position of the self as part of the organization where there are institutional goals that must be implemented and also the position of the self in his role as a professional educator who also has an obligation to realize instructional goals.

When teachers try to align themselves with existing demands, this is where cognitive processes occur that ultimately lead to a series of decisions both in the form of actions and behavior as an effort to accommodate these 
demands. In a more concrete form in learning activities, the form of teacher actions and behavior reflected in the determination of strategies, methods, approaches, learning resources, learning tools and media, forms of evaluation, and treatment given to students in the form of encouragement and guidance to maximize learning activities that is what is meant by the efficacy of teaching. When the teacher feels confident about the actions and behaviors that are set and he also feels confident that the abilities possessed will be able to carry out successfully on what has been determined, then the essence of teaching efficacy in the teacher occurs.

To foster teaching self-efficacy, teachers need a long process that goes through various stages and is influenced by various factors before arriving at a condition where the teacher makes himself a model of behavior for himself and others. One factor that can foster teaching efficacy is the empowerment of principals who play instructional leadership. Principals who are good instructional leaders develop a deep appreciation for the potential artistry of an instructional conference with a teacher (Southworth, 2002: 80).

In strengthening the efficacy of teaching through optimizing the role of instructional leadership, Hallinger (2009: 7-8) suggests five forms of activities for school principals to do, namely: (1) at this school the mission was absolutely clear. It was written down and visible around the school; (2) focused on academic development appropriate to the needs of this particular school population; (3) the mission set a priority for the work of teachers; (4) it was known and accepted as legitimate by teachers throughout the school; (5) the mission was articulated, actively supported, and modeled by the principal.

A further indication of the low influence of instructional leadership on teaching selfefficacy is the low ability of principals in managing curriculum and instructional structures.
Managing curriculum and instructional programs are the activities of school principals in harmonizing and overseeing curriculum implementation and learning in schools. This activity consists of three activities that must be carried out routinely namely evaluating learning (evaluating instruction), coordinating the curriculum (coordinating the curriculum), and monitoring student progress (monitoring student progress).

Principals in managing curriculum and learning programs are positioned as a control of teaching towards learning that occurs in the classroom; assess teaching success, conduct assessment of teaching performance, identify teacher strengths and weaknesses in teaching, identify teacher needs in teaching, monitor student success in learning, and arrange continuous improvement programs in an effort to improve teacher's ability to teach. Therefore, support in the form of good knowledge from the principal about the teaching and learning process-pedagogical knowledge as well as an understanding of school management-knowledge based management is absolutely necessary. This statement is consistent with the opinion of Hoy \& Miskel (2009) which states that principals in managing curriculum and instructional programs coordinate and supervise the school curriculum and teaching process by stimulating, encouraging or motivating, supervising, evaluating, and monitoring the teaching and learning process.

Suggestions, input, instructions, forms of support, and provision of facilities needed by teachers in teaching are essentially sources of efficacy for teachers that occur between the principal and teachers. The results of monitoring and evaluation submitted by the principal are not justifications for the teacher's condition, but rather the form of teaching improvement and the efforts of the principal to align the demands of the profession with the demands of the institution. Meanwhile, the form of support and provision of teaching facilities is the principal's effort to provide alternatives to teachers in determining which 
resources are available in schools that can be used in learning.

Being an instructional leader who is able to manage curriculum and teaching programs well is not enough to be supported only by the knowledge of learning concepts, but it takes more than that. Instructional leaders must also have the ability to manage teachers and staff, the learning environment, and the physical resources that the school has. The two main conditions above must be able to be implemented in every principal's activity. Vruggink (2010: 322)(reference??) which describes these two abilities into nine criteria, including: (1) a strong commitment to improving instruction; (2) demonstrated leadership ability; (3) a knowledge of effective staff development (4) experience in curriculum development; (5 ) skills in interpersonal relations; (6) an ability to relate to the community and to communicate effectively; (7) a determination to delegate non-instructional matters; (8) an ability to create an environment to initiate and maintain educational change, and (9) a commitment to assessment of programs.

\section{CONCLUSION/RECOMENDATION}

Instructional leadership influences teaching self-efficacy. The effect of instructional leadership on the teaching efficacy of teachers is significant even though it is classified as weak. The weak influence of instructional leadership on teacher teaching efficacy occurs due to the weak relationship between variables and instructional leadership indicators on teaching self-efficacy. From three leadership indicators measured, statistically the relationship of the three indicators to teaching efficacy is included in the low category.

Practically, one of the factors that causes the low influence of instructional leadership on teaching self-efficacy is the suboptimal role of the principal as an instructional leader. Instructional leadership is still played formatively and has not become a major element for school principals in the successful implementation of education in schools.

This condition occurs because the school principal is still limited to an additional task of the teacher so that the role and function cannot run optimally. Instructional leadership is leadership that focuses its activities on achieving school goals, enhancing learning activities, and building a conducive academic culture so that teachers and students can develop their skills and abilities optimally.

\section{REFERENCES}

Ashton, P. T., \& Webb, R. B. (1986). Making a difference: Teachers sense of efficacy and student achievement. New York: Longman.

Bandura, Albert. (1997). Exercise Of Personal and Collective Efficacy in Changing Societies, dalam Albert Bandura (Editor), Self-Efficacy in Changing Society (hlm. 1-45). UK: Cambridge University Press

Blasé, Joseph \& Blasé, Jo. (2000). Effective Instructional Leadership: Teacher's perspectives on how principals promote teaching and learning in schools. Journal of Educational Administration, Vol. 38, No. 2, hlm. 130-141.

DeChenne, Sue Ellen \& Enochs, Larry. (2010). Measuring the Teaching Self-Efficacy of Science, Technology, Engineering, and Math Graduate Teaching Assistants. Proceeding. Oregon State University

Fancera, Samuel F \& Bliss, James R. (2011). Instructional Leadership Influence on Collective Teacher Efficacy to Improve School Achievement. Leadership and Policy in Schools, Vol. 10, hlm.349-370.

Flores, B., \& Clark, E. R. (2004). A critical examination of normalistas selfconceptualization and teacher-efficacy. Hispanic Journal of Behavioral Sciences, Vol. 26, hlm. 201-230.

Gavora, P. (2001). Slovak Pre-Service Teacher SelfEfficacy: Theoritical and Research Considerations. The New Educational Review. Vol. 21, No. 2 (2010), hlm. 17-30.

Gibson, S., \& Dembo, M. H. (1984). Teacher efficacy: A construct validation. Journal of Educational Psychology, Vol. 76, hlm. 503-511.

Hallinger, Phillip. (2003). Leading Educational Change: reflections on the practice of instructional and transformational leadership. Cambridge Journal of Education Vol. 33, No. 3. Mahidol University, Bangkok

Hallinger, Phillip. (2009). Leadership for 21st Century Schools: From Instructional Leadership to Leadership for Learning. China: he Hong Kong Institute of Education 


\section{Muflih Ma'mun, et al. / Journal of Educational Administration Research and Review / Vol. 3 No. 1 June 2019}

Hill, Peter W., (2002). What Principals Need to Know About Teaching and Learnin. Dalam Marc S. Trucket \& Judy B. Codding, The Principal Challenge: Leading and Managing Schools in an Era Accountability (hlm. 43-75) USA: JosseyBass

Hoy, Wayne K \& Miskel, Cecil G. (2014). Administrasi Pendidikan: Teori, Riset, dan Praktik (Edisi 9). Yogyakarta: Pustaka Pelajar

Klump, Jennifer \& Barton, Rhonda. (2007). Building Instructional Leadership. Principal's Research Review, Vol. 2 (5), hlm. 1-6.

Kristine A.,Hipp. (1996). Teacher Efficacy: Influence of Principal Leadership Behavior. (Paper). New York: Departement of Educational Leadership, Ball State University

Maddux, James E. (1995). Self-Efficacy, Adaption, and Adjustment: Theory, Research and Application. New York: Springer

Miller, William C \& Vruggink, Elmer. (2010). Needed: A Building-Level Instructional Leader, The Clearing House. A Journal of Educational Strategies, Issues and Ideas, 56:7, 321-323. UK: Routledge

Moss, Connie M \& Brookhart, Susan M. (2009). Advancing Formative Assessment In Every Classroom: A Guide For Instructional Leaders. Virgini:ASCD

Palmer, D.H. (2006). Sources of Self-efficacy in a Science Methods Course for Primary Teacher Education Students. Research in Science Education (2006) 36: hlm. 337-353

Plessis, du Pierre. (2013). The Principal as Instructional Leader: Guiding Schools to Improve Instruction. Education As Change Journal, Vol. 17, hal. 79-92.

Rew, Joshua W. (2013). Instructional Leadership Practices And Teacher Efficacy Beliefs: CrossNational Evidence From Talis. (Dissertation).
Florida State University: Departemen of Educational Leadership and Policy Study

Sahin, Semiha. (2011). The Relation Between Instructional Leadership Style and Schoo Culture. Educational Sciences: Theory and Practice Journal, Vol. 11, hlm. 1920-1927.

Schunk, Dale H. (1995). Self-Efficacy and Education. Dalam James E. Maddux, Self-Efficacy, Adaption, and Adjustment: Theory, Research and Application (hlm. 281-300). New York: Springer

Southworth, Geoff. (2002). Instructional Leadership in Schools: Reflections and empirical evidence. School Leadership \& Management, Vol. 22, No. 1, pp. 73-91. UK: Routledge

Tschannen-Moran, Megan \& K. Hoy, Wayne. (1998). Teacher Efficacy: It's Meaning and Measure. Review of Educational Research, Vol. 68, No. 2, hlm. 202-248

Wheatley, K. F. (2005). The case for reconceptualizing teacher efficacy research. Teaching and Teacher Education Journal, Vol. 21, hlm. 1-19

Yeh, Yu-Chu. (2006). The Interactive effects of personal traits and guided practices on preservice teacher's changes in personal teaching efficacy. British Journal of Educational Technology, Vol. 37, No. 4, hlm. 513-526.

Yeo, Lay See.,dkk. (2008). Teacher Efficacy In the Context of Teaching Low Achieving Students. Curr Psychol, Vol. 27, hlm. 192-204

Zepeda, Sally J \& Kruskamp, Bill. (2007). High School Department Chairs-Perspectives on Instructional Supervision. The High School Journal, Volume 90, Number 4, April-May 2007, hlm.44-54

Zimmerman, Barry J. (1997). Self-Efficacy and Educational Development-onAlbert Bandura, Self-Efficacy in Changing Society (hlm. 202-231). UK: Cambridge University Press. 